\title{
PRESENCIA DEL ARZOBISPO GANDÁSEGUI EN INSTITUCIONES ECLESIÁSTICAS NACIONALES (1920-1937)
}

\author{
POR \\ Jesús MARÍA PALOMARES IBÁÑEZ \\ Universidad de Valladolid \\ jmpalom@gmail.com
}

\section{RESUMEN}

Dentro del episcopado español del primer tercio del siglo xx destaca la personalidad de Remigio Gandásegui (1871-1937). Preconizado obispo cuando tenía 34 años para la sede de Ciudad Real, diez años después gobernó la diócesis de Segovia. Desde 1920 y hasta su muerte rige la archidiócesis de Valladolid. Será ahora, y en virtud de su categoría arzobispal, cuando participe directamente en los dos organismos nacionales de la iglesia española que considera este artículo.

PalABRAS CLAVE: Iglesia española siglo xx, Archidiócesis de Valladolid, Junta Delegada del Real Patronato, Conferencia de Metropolitanos.

\section{ARCHBISHOP GANDÁSEGUI'S PRESENCE IN NATIONAL ECCLESIASTICAL INSTITUTIONS (1920-1937)}

\begin{abstract}
Remigio Gandásegui (1871-1937) stands out among the Spanish bishops of the first third of the twentieth century. Appointed bishop of the diocese of Ciudad Real when he was 34 years old, he ruled the diocese of Segovia ten years later. From 1920 until his death he governed the Archdiocese of Valladolid. It was then, in his archiepiscopal category, when he participated directly in the two Spanish national church organizations we are considering.
\end{abstract}

KEY WORDS: Spanish Church in twentieth century, Archdiocese of Valladolid, Royal Patronage Executive Board, Conference of Metropolitans.

$\begin{array}{ll}\text { Recibido/Received } & 11-06-2014 \\ \text { Aceptado/Accepted } & 20-09-2014\end{array}$

Cuando Remigio Gandásegui, anterior obispo preconizado a la edad de 34 años para la diócesis de Ciudad Real y después trasladado a la de la Segovia, en 1920 tomó posesión de la sede metropolitana de Valladolid, esta nueva categoría arzobispal le habilitó para culminar la carrera eclesiástica. Y, al mismo tiempo, además de otros cargos (senador por derecho propio, miembro de la Asamblea) participar plenamente en dos nuevas instituciones eclesiásticas nacidas en fechas inmediatas: la Junta Delegada del Patronato Regio Eclesiástico y la Conferencia de Metropolitanos. ${ }^{1}$

1 Para una biografía completa del obispo y arzobispo Gandásegui su obra pastoral, social y política, remitimos a la monografía de Berzal de la Rosa, Enrique.1999. Remigio Gandásegui (1905-1937) Un obispo para una España en crisis, Madrid: BAC.

\section{la junta Delegada del Real Patronato Eclesiástico (1924-1930)}

El proceso de nombrar los obispos españoles en los últimos tres siglos es un asunto que venía de siglos atrás (el derecho de presentación) y estuvo vigente y confirmado en los concordatos de 1753, 1851 y 1953. Respecto del patronato real su derecho terminaba con la presentación del candidato al Papa, quien sancionaba la propuesta regia nombrando al obispo que era preconizado para una sede (diócesis) concreta. El proceso concluía con la ordenación episcopal y la toma de posesión del nuevo prelado. Durante el reinado de Alfonso XIII seguía vigente este sistema bajo amparo del concordato de 1851. Por ello, el Rey -su Gobierno- interviene en la presentación de obispos y beneficios eclesiásticos sobre ternas propuestas por los 
ordinarios respectivos y cuyos candidatos pasaban por esta trama antes de su nombramiento. ${ }^{2}$ A lo largo del periodo constitucional de la Restauración (1876-1923), recuerda Zamora García, existía un consenso, o simple respeto a una tradición secular, entre la Iglesia y el Estado sobre la conveniencia de mantener sus mutuos privilegios y, en consecuencia, el derecho de presentación. ${ }^{3}$ Ello no impedía que el propio episcopado cuestionase dicho derecho o privilegio. Con todo, el sistema siguió vivo hasta producirse el golpe de Estado del general Primo de Rivera.

Para salir al paso de los abusos que, en su caso, ocasionaba el sistema anterior, Primo de Rivera y dentro del conjunto de novedades ("regeneradoras" para algunos, respecto de los gobiernos constitucionales anteriores) introducidas por el dictador, tras su golpe de Estado en septiembre de 1923, aparece la Junta Delegada del Real Patronato Eclesiástico. Esta institución, cuya vigencia apenas duró un sexenio, nació al promulgarse el RD de 10 de marzo de 1924. Según Cárcel Ortí esta Junta era innovadora y cuyo desafío era evitar injerencias de los políticos en asuntos internos de la Iglesia y también frenar la fiebre por alcanzar cargos que podía percibirse entre los clérigos. ${ }^{4}$ El empeño era cierto, aunque la Santa Sede hubiera preferido que la Corona renunciara a este privilegio. ${ }^{5}$

El nuevo organismo, cuya tarea era seleccionar candidatos para obispos y otros beneficios eclesiásticos, pretendía incorporar nuevos aires respecto del pasado secular. Con todo, seguía en pie el privilegio tradicional reservando al Rey (Gobierno) respecto del ascenso / traslado / promoción de arzobispos o recolocación entre sedes episcopales. EI mismo Real Decreto puntualizaba sus funciones, reservando a la presidencia, arzobispo y los dos obispos proponer los candidatos al episcopado, mientras que los cuatro vocales restantes lo hacían respecto de las prebendas y beneficios eclesiásticos. La Junta debía elaborar a comienzos del año una relación de episcopables (con la información y méritos atribuidos a cada uno de ello) respecto de las vacantes previsibles. Los resultados, siempre con carácter reservado, se ponían en manos del Ministerio de Gracia y Justicia y su propuesta al Monarca, quien mantenía su derecho de presentación, aparte de la posterior promoción de arzobispos y traslados de obispos de una sede a otra. Pervivía, como ha señalado José Andrés-Gallego el regalismo que, con sus vaivenes y, hasta el Acuerdo básico entre la Santa Sede y el Estado español de 28 de junio de 1978, mantenía lo concordado anteriormente y precisando los limites sobre los obispos titulares, quedando aparte los obispos auxiliares. ${ }^{6}$

\footnotetext{
2 Andrés-Gallego, José. 1999. La Iglesia en la edad contemporánea, 1. 1800-1973:140ss. Madrid: Ediciones Encuentro.

3 Zamora García, F.J. 2011: "Los nombramientos episcopales durante la Dictadura del general Primo de Rivera". Anuario Jurídico y Económico Escurialense, XLIV: 551-566.

4 Como dice el texto legal: "Marcando reglas y normas para la provisión de destinos y la concesión de ascensos, dejando el menor margen a la recomendación y a la influencia, que tantos estragos han hecho en la fe profesional y en la carrera pública".

5 Cárcel Ortí. V.1996. "Iglesia y Estado durante la Dictadura de Primo de Rivera". Revista de Derecho Canónico, vol. 45: 215, Madrid.

6 Cárcel Ortí, V.1996 "Ejercicio del privilegio de presentación de obispos por el general Franco", II Atti del X symposium canonistico-romanistico, 24-128 aprile 1995.
}

Siendo esto así, el respeto básico de los informes de la junta dejaba un resquicio de discrecionalidad que pudo usar el Gobierno influyendo en la configuración del episcopado.

Desde que se publicó el Decreto, la Junta recibió juicios dispares. Zamora García recuerda las posturas que pudieron apreciarse en la prensa periódica del momento. ${ }^{7}$ Es el caso de los diarios: El Sol, El Debate o El Universo. Aunque cabe recordar los elogios por sus frutos, lo cierto es que las decisiones de la Junta también fueron contestadas (ob. Ávila) respecto de la selección que presentaron los prelados, singularmente en la circunscripción de Cataluña. Y que, en concreto, denunció el cardenal Vidal i Barraquer ante el papa Pío XI, evidenciando que la política se percibía presente en algunas decisiones. ${ }^{8}$

A través del Real Decreto se detalla la composición y funciones del organismo. Integrado por clérigos como delegados del Rey cuya misión consistía en proponer a la Coronan las personas capaces de asumir cargos eclesiásticos: presbíteros que fueran elevados al episcopado o recibieran otras prebendas y beneficios vacantes, cuya provisión estaba reservada a la Corona. ${ }^{9}$ La Junta, encabezada por su presidente, el cardenal arzobispo-primado de Toledo, estaba compuesta por dos bloques o grupos. Al primero correspondía informar sobre clérigos "mitrables" o "episcopables" (expresiones contenidas en la correspondencia que mantiene el presidente y los vocales) y eran sus vocales un arzobispo y dos obispos titulares, con los suplentes correspondientes. Todos ellos elegidos por los metropolitanos y obispos. Su cometido se limitaba a elaborar el catálogo de posibles nuevos obispos. Mientras que la Junta no intervenía en los traslados entre obispos de una sede a otra, ni promover arzobispos reservados a la Corona. El segundo grupo sumaba tres vocales (titulares y suplentes): un prebendado dignidad, un canónigo y un beneficiado del cabildo catedral o colegiata del Reino, elegidos por cada categoría. Ambos grupos debían renovarse cada dos años. Si quedase vacante la presidencia, con carácter provisional correspondería al arzobispo más antiguo que no perteneciera a la Junta.

Ateniéndose a la normativa, la primera Junta delegada comenzó sus funciones en el mismo año de su creación (1924), presidida por el cardenal Enrique Reig Casanova, arzobispo primado de Toledo. Remigio Gandásegui intervino desde primera hora por haber sido elegido entre los metropolitanos y estuvo acompañado por dos obispos residenciales.

Puesto que, salvo la presidencia, todos los vocales debían renovarse cada dos años, según disponía el RD, a finales de 1925, fueron renovados. Los prelados debían emitir su voto por carta o por oficio dirigidos al cardenal arzobispo de

7 Zamora García, F. J. 2011, 551-556.

8 Muntanyola, Ramón.1971:105-182. Vidal i Barraquer: el cardenal de la paz, Barcelona.

9 En el caso de obispos-coadjutores, según Gaceta 8.11.1925: 739: "A propuesta del Jefe del Gobierno, Presidente interino del Directorio Militar, y de acuerdo con éste, con el Consejo de Estado y con el Nuncio Apostólico, se decreta: Para los casos del nombramiento de obispo auxiliar, en casos excepcionales que la Santa Sede aconseje concederle el derecho de sucesión: se procederá al nombramiento de obispo-coadjutor. En este caso para que no sufra detrimento el derecho de patronato de Su Majestad Católica, la presencia de personas aptas para el cargo correspondiente a la Corona, de la misma manera que si se tratara de proveer una sede vacante". Y por eso exige la previa presentación de la Corona. 
Toledo, quien declarará elegidos los clérigos que obtuvieran la mayoría relativa de sufragios. Los vocales arzobispos serían elegidos por los metropolitanos, y los vocales obispos por los sufragáneos. ${ }^{10}$ Idéntico proceso seguían los demás vocales: elegidos por las dignidades, por los canónigos y por los beneficiados de todas las catedrales y colegiatas de España. Este proceso mediante voto corporativo se computaba en cada cabildo a razón de un voto por cada clase de aquellas que pertenecieran los elegidos. También entran en el bloque anterior otras categorías: capellanes de Reyes y otros no pertenecientes a cabildo catedral o colegial, que lo harán como los canónigos sufragáneos. Los resultados debían notificarlos a cada uno de los metropolitanos. Esta norma se cumplirá a rajatabla. Así lo confirman diversos escritos conservado en el Archivo de Curia, que el cardenal Segura remite al arzobispo Gandásegui en el bienio final de la Junta.

La primicia sobre cómo quedó constituida en su arranque la publica el BOAV, cuando afirma haber sido creada en virtud del Real Decreto, cuyo texto, por cierto, no incorpora. Dicha relación sólo aporta los títulos de sus integrantes, sin ofrecer el nombre, excepto en tres de sus miembros. ${ }^{11}$ Cabe presumir que todos cumplieron la elección reglamentaria. Teniendo en cuenta estas salvedades, la Junta queda así:

\begin{tabular}{|l|l|l|}
\hline Presidente nato & $\begin{array}{l}\text { Cardenal arzobispo } \\
\text { de Toledo }\end{array}$ & \\
\hline Vocales numerarios & & Vocales suplentes \\
\hline $\begin{array}{l}\text { Arzobispo } \\
\text { de Valladolid }\end{array}$ & $\begin{array}{l}\text { Arzobispo } \\
\text { de Valencia }\end{array}$ \\
\hline Obispo de Salamanca & & Obispo de Ávila \\
\hline Obispo de Pamplona & & Obispo de Badajoz \\
\hline $\begin{array}{l}\text { Arcipreste SIM } \\
\text { de Zaragoza }\end{array}$ & & $\begin{array}{l}\text { Arcipreste SIM } \\
\text { de Jaén }\end{array}$ \\
\hline $\begin{array}{l}\text { Víctor Marín can., } \\
\text { SIM de Toledo }\end{array}$ & Doctoral de Toledo \\
\hline $\begin{array}{l}\text { Acisclo de Castro } \\
\text { beneficiado } \\
\text { de Zamora }\end{array}$ & & $\begin{array}{l}\text { Jaime Juvete } \\
\text { beneficiado } \\
\text { de Toledo }\end{array}$ \\
\hline
\end{tabular}

De momento, el director de la publicación no aporta más detalles. Incluso omite felicitar al arzobispo, cuando por otras encomienda (cuando fue designado senador por derecho propio) nunca olvida felicitar al prelado. ${ }^{12}$

Un mes después, el diario oficial de la archidiócesis anuncia las primeras prebendas vacantes. Abría paso esta primera convocatoria para proveer los siguientes cargos eclesiásticos:

Deán de la SIM de Tarragona

Deán de la SIC de Mondoñedo

Arcediano de la SIC de Lugo

Canónigo de la SIC de Badajoz

Beneficiado de la SIC de Badajoz

Beneficiado de la SIC de Cuenca

En meses sucesivos, seguirá haciéndolo hasta suprimirse esta institución, precisando la denominación y requisitos de cada plaza sobre las que la JRP debía pronunciarse

\footnotetext{
10 Artículo 6 del RD de 9 de marzo de 1924.

11 Boletín Oficial Eclesiástico del Arzobispado de Valladolid (en adelante BOAV) №. 6, 20.05.1924, pág. 94.

12 BOAV no. 4, 03.03.1922: 47.
}

anualmente dos veces. Esta misma fuente advierte el itinerario, seguido por quienes pretendieran obtener las prebendas vacantes cuya provisión correspondía a la Corona. ${ }^{13}$ Otro Decreto (10 diciembre 1925) regulará en ocho categorías estos concursos. Desde la primera, abierta por los deanes de sufragáneos y dignidades metropolitana, hasta la octava relativa a párrocos de entrada, rurales y otros. Todo estaba detallado, dirá el ministro Galo Ponte: "para evitar que los aspirantes aparezcan confundidos de manera que se hace muy difícil su justa apreciación".

\section{CONVOCATORIAS PUBLICADAS EN EL BOAV}

\begin{tabular}{|l|c|}
\hline BOAV & Concurso de vacantes \\
\hline № 8, 01.07.1924,113. & 6 \\
\hline № 10, 14.08.1924 136 & 4 \\
\hline № 5, 20.05,1925, 51 & 9 \\
\hline № 13, 21.12.1925, 130 & 10 \\
\hline № 3, 26.02.1926,34 & 10 \\
\hline № 4, 18,03.1926, 39 & rectificación $^{14}$ \\
\hline № extra 05.05.1926, 68 & $7^{2}$ \\
\hline № 2, 24.02.1927, 19 & 10 \\
\hline № 7,06.06.1927, 69 & 16 \\
\hline № 10, 05.09.1927, 87 & 7 \\
\hline № 1,11.02.1928,22 & 12 \\
\hline № 5, 11.06.1928, 87 & 6 \\
\hline № 7, 15.09.1928,107 & 9 \\
\hline № 10, 10.11.1928, 152 & 8 \\
\hline №.2, 05.03.1929, 27 & 7 \\
\hline № 5, 16.05.1929,66 & 9 \\
\hline № 9, 20.08.1929, 108 & 11 \\
\hline
\end{tabular}

La relación anterior no tiene presente las propuestas exclusivas del primer sector (presidente y obispos) de la Junta responsable de proponer nuevos obispos, cuya cifra en este decenio, sin incluir los obispos auxiliares, supero la veintena. Entre los promovidos estuvo el futuro primado Isidro Gomá, preconizado para la diócesis de Tarazona. En cualquier caso, ambos cometidos (obispos y otras prebendas) manifiestan el trabajo acumulado por la Junta y singularmente al arzobispo vallisoletano, pues perteneció a este organismo desde el principio hasta el final. Incluso, debido a la enfermedad que padeció en sus últimos meses el cardenal Reig Casanova, debió hacerse cargo de convocar y presidir en ausencia del primado la junta delegada.

Según la preceptiva renovación de sus vocales, las segundas elecciones para el periodo 1 de enero de 1926 a 31 de diciembre del año siguiente, arrojaron estos resultados: ${ }^{15}$

13 BOAV no. 8, 01.07.1924:113. "Para que llegue a conocimiento de cuantos pudieran tener interés en ello, el excelentísimo y reverendísimo señor arzobispo ha dispuesto se publique en este número del Boletín Oficial Eclesiástico la siguiente comunicación que ha recibido de la susodicha Junta, a los efectos correspondientes y cuyo texto se traslada". Así quedaba cumplido lo dispuesto en el artículo 60 del RD, que el secretario de la Junta trasladaba a su vez a los vocales, con esta expresión: "Tengo el honor de comunica a VE por orden del eminentísimo señor cardenal presidente de la Junta".

14 Sobre el anuncio anterior del deanato de la catedral de Segovia.

15 También el BOAV n. 13, 21.012.192:136-137 incluye, entre las disposiciones de Poderes Civiles del Ministerio de Gracia y Justicia, lo que 
Junta Delegada del Real Patronato Eclesiástico $(1926-1927)^{16}$

\begin{tabular}{|l|l|l|}
\hline $\begin{array}{l}\text { Presidente } \\
\text { nato: }\end{array}$ & $\begin{array}{l}\text { Enrique, cardenal Reig } \\
\text { Casanova, arzobispo } \\
\text { de Toledo }\end{array}$ & \\
\hline Vocales & Titular & Suplente \\
\hline & $\begin{array}{l}\text { Remigio Gandásegui, } \\
\text { arzobispo de Valladolid }\end{array}$ & $\begin{array}{l}\text { Rigoberto Domenech, } \\
\text { arzobispo de Zaragoza }\end{array}$ \\
\hline & $\begin{array}{l}\text { Mateo Múgica, obispo } \\
\text { de Pamplona }\end{array}$ & $\begin{array}{l}\text { Cruz Laplana, obispo } \\
\text { de Cuenca }\end{array}$ \\
\hline & $\begin{array}{l}\text { Ramón Pérez, obispo } \\
\text { de Badajoz }\end{array}$ & $\begin{array}{l}\text { Enrique Plá i Deniel, } \\
\text { obispo de Ávila }\end{array}$ \\
\hline & $\begin{array}{l}\text { J. Pellicer, arcipreste } \\
\text { SIC Zaragoza }\end{array}$ & $\begin{array}{l}\text { J. Polo, deán SICP } \\
\text { Toledo }\end{array}$ \\
\hline & $\begin{array}{l}\text { V. Martín, can. SICP } \\
\text { Toledo }\end{array}$ & $\begin{array}{l}\text { J. Mérida, canónigo de } \\
\text { Sacromonte Granada }\end{array}$ \\
\hline & $\begin{array}{l}\text { F. Ibave, beneficiado } \\
\text { de Toledo }\end{array}$ & $\begin{array}{l}\text { V. Sacristán, beneficiado } \\
\text { de Sigüenza }\end{array}$ \\
\hline
\end{tabular}

La postrera renovación tuvo efecto en noviembre de 1929, cuando Gandásegui volverá a ser reelegido y el cardenal Segura se apresura a comunicárselo:

"Tengo el honor de poner en conocimiento de VE que verificado, a tenor de las disposiciones vigentes, el escrutinio para la elección de Vocales de la Junta Delegada de Real Patronato Eclesiástico, ha sido VE elegido para Vocal Propietario de la misma en el próximo bienio. Lo que tengo la satisfacción de participarle a los efectos consiguientes. ${ }^{17}$

Con ello, la Junta quedaba constituida con estos miembros:

\begin{tabular}{|l|l|l|}
\hline $\begin{array}{l}\text { Presidente } \\
\text { nato }\end{array}$ & $\begin{array}{l}\text { Pedro, cardenal } \\
\text { Segura, arzo de Toledo }\end{array}$ & \\
\hline Vocales & Propietario & Suplente \\
\hline & $\begin{array}{l}\text { Remigio Gandásegui, } \\
\text { arzobispo de Valladolid }\end{array}$ & $\begin{array}{l}\text { Prudencio Melo } \\
\text { Alcalde, arzobispo de } \\
\text { Valencia }\end{array}$ \\
\hline & $\begin{array}{l}\text { Mateo Múgica, obispo } \\
\text { de Vitoria }\end{array}$ & $\begin{array}{l}\text { Francisco Frutos } \\
\text { Valiente, obispo de } \\
\text { Salamanca }\end{array}$ \\
\hline & $\begin{array}{l}\text { Enrique Plá i Deniel, } \\
\text { obispo de Ávila }\end{array}$ & $\begin{array}{l}\text { Cruz Laplana, obispo } \\
\text { de Cuenca }\end{array}$ \\
\hline & $\begin{array}{l}\text { F. Degano, deán SIC } \\
\text { Calahorra }\end{array}$ & $\begin{array}{l}\text { B. Torres, deán de } \\
\text { Palencia }\end{array}$ \\
\hline & $\begin{array}{l}\text { V. Martín, canónigo de } \\
\text { Toledo }\end{array}$ & $\begin{array}{l}\text { J. Basés, canónigo de } \\
\text { Toledo }\end{array}$ \\
\hline & $\begin{array}{l}\text { E. Rodríguez, } \\
\text { beneficiado de Madrid }\end{array}$ & $\begin{array}{l}\text { N. Barber, beneficiado } \\
\text { de Madrid }\end{array}$ \\
\hline
\end{tabular}

se dice al cardenal de Toledo presidente de la Junta y como resultado de las elecciones para la renovación de los vocales verificada para cumplir el artículo 3 del RD, Su Majestad se ha servido nombrar vocales de la Junta para el periodo 1 de enero de 1926 y 31 de diciembre de 1927

16 Los dos beneficiados titular y suplente figuran sustituidos por Emilio Rodríguez, beneficiado de Madrid y José María Lasa, ídem, en la notificación que el 4 de mayo de 1927 dirige desde Toledo Juan José Santander a Valero Caudevilla (Arzobispado de Valladolid).

17 Archivo de Curia de Valladolid. Documentos del arzobispo Gandásegui (ACVAG). Toledo, 28.11.1929. Pedro, cardenal Segura arzobispo de Toledo a Excmo y Rvmo Señor arzobispo de Valladolid.
Por lo que concierne al prelado vallisoletano, en la breve historia de esta institución Gandásegui desempeñó un papel importante junto a los cardenales primados que la presidieron. Estos fueron sucesivamente los cardenales Reig Casanova, Vidal y Barraquer (mientras quedó vacante la sede toledana por muerte del anterior), y su sucesor Pedro Segura. Según indicamos a continuación, como representante de los metropolitanos españoles, Gandásegui intervino desde que nació la Junta hasta su extinción. En el caso del cardenal Reig, el primer trienio compartió las convocatorias y asuntos en estrecha relación con el presidente. La enfermedad del purpurado le dará ocasión para asumir un rol mayor. Esto sucede en 1927, cuando el arzobispo de Valladolid reciba sucesivamente información directa acerca del delicado estado de salud del primado. ${ }^{18}$ Un mes después, hospitalizado en Ciempozuelos, avala la convocatoria. ${ }^{19}$ Por ello, debía tomar las riendas de la reunión, si bien antes Gandásegui cortésmente visitará y conversará con el purpurado-"iré a saludarle y hacer los comentarios oportunos"-.$-^{20}$ El cardenal Reig falleció el 25 de agosto. El Boletín de la archidiócesis vallisoletana incluye un merecido elogio del difunto. ${ }^{21}$

Desde entonces y hasta primeros del año siguiente permanece vacante la sede toledana y, de forma interina, la Junta delegada será presidida por el cardenal de Tarragona Vidal y Barraquer, quien mantuvo una fluida relación epistolar con Gandásegui. Tras la convocatoria del 10 de octubre, desde Tarragona, el día 27 de diciembre de 1927, Gandásegui recibió la lista de mitrables con los nombres y datos facilitados por los Ordinarios. Ahora bien, pendiente del nombramiento del nuevo primado, Vidal considera conveniente -Gandásegui opina igual-, demorar la próxima reunión de la Junta, para ceder la presidencia al recién incorporado arzobispo primado. ${ }^{22}$ Un par de años fue el tiempo que Pedro Segura presidió la Junta volviéndose a repetirse los contactos habituales y petición de asesoramiento. Dos

18 ACVAG. Toledo 02.05.1927. Cardenal Reig a Arzobispo Gandásegui. Para que convoque la JRP para la provisión de vacantes, porque "no se puede aún calcular la duración de la enfermedad que me impide salir de mis habitaciones". Por ello, se le envían los informes recibidos y la relación de solicitantes.

19 ACVAG. Ciempozuelos 27.06.1927. Cardenal Reig a arzobispo Gandásegui: "He pedido informes a los prelados de las últimas prebendas anunciadas, pero como todavía no estoy bien no podré presidir la Junta. Como en la anterior ocasión, le enviaré los informes y pido a don Juan José Santander envíe a Usted las listas de los concursantes".

20 ACVAG. Ciempozuelos 02.07.1927. Cardenal de Toledo al arzobispo Gandásegui. "Me parece bien la fecha de la Junta, siento que se moleste viniendo a verme la víspera de la Junta y se lo agradezco como no puede Usted figurarse. Doy orden a Toledo para que le envíen todos los informes".

21 BOAV no. 10, 05.09.1927: 88.

22 ACVAG. Sarriá, 10 de enero de 1928. Cardenal de Tarragona a Arzobispo de Valladolid. "Muy venerado Hermano y querido amigo: En esta donde me encuentro para presidir las Conferencias de Prelados de esta provincia recibo su muy grata del 4 del corriente. Ante la proximidad, según dicen los periódicos, de la entrada en Toledo del eminentísimo señor Segura, opino como Usted que precede aplazar todo lo que a la Junta D. del R. Patronato se refiere, hasta que él pueda hacerse cargo de su presidencia. Muy agradecido por su interés por mi restablecimiento, que aún no del todo cabal como debiera, me reitero affmo su ho y amigo". 
ejemplos son suficientes para ilustrarlos. Antes de convocar la asamblea, se dirige a Gandásegui diciéndole que: "también le agradecería envíe los puntos que a su juicio conviene tratar para fijar los temas (...) y también espero de su bondad me comunique la práctica hasta ahora seguida, en orden a la asistencia a las Conferencias, respecto de los arzobispos preconizados y que todavía no se han posesionado de sus sedes". ${ }^{23}$ Un año después vuelve a consultarle sobre otro asunto. "Mi venerado Hermano y querido amigo: Celebrada la Junta, ha quedado intranquilidad al obispo de Ávila sobre como se resolvió la maestrescolía de Santander. Y como lo resolvió con la copia antes enviada al ministro. Espero recibir su parecer, pues es un caso que nos convenía obrara con diafanidad". ${ }^{24}$

El arzobispo de Valladolid intervendrá en el último bienio participando en todas las reuniones. Al final, compartirá con el primado el disgusto por la extinción de la Junta.

Ya fuera del mandato del general Primo de Rivera, otro Real Decreto del Ministerio de Gracia y Justicia de 16 de junio de 1930 disolvía la Junta delegada del Real Patronato eclesiástico: ${ }^{25}$

Artículo1ㅇ. A partir de la publicación de este Real Decreto cesará la actuación de la JDRP, creada por RD de 10.3.24, quedando disuelta y expresando a sus ilustres miembros Mi Satisfacción por el celo y la lealtad con que han desempeñado su cometido.

Artículo 20. Todas las vacantes de prebendas eclesiásticas existentes en la actualidad o que en lo sucesivo se produzcan, cuya provisión pertenece a la Corona, en virtud de las disposiciones concordadas serán provistas en la forma que dichas disposiciones preceptúen.

Artículo 3 Quedan derogados los Reales Decretos de 10 de marzo de 1924 y 14 de diciembre de 1925 y demás preceptos concordantes".

A propósito del cese de la Junta el cardenal Segura se pronuncia, en nombre de los demás vocales, en una carta -mezcla de agradecimiento, pero también de queja- dirigida desde Roma el 28 de junio de 1930 al Ministro de Gracia y Justicia, cuya copia conservó Gandásegui, en estos términos:

"Excmo Sr: Recibo aquí en Roma su atenta carta del 16 del actual y la comunicación de Real Orden del RD de la misma fecha en que se deroga el de 10 de marzo d 1924 por el cual se creó la Junta Delegada del Real Patronato Eclesiástico.

He de agradecer a VE el acto de deferencia que ha tenido conmigo al quererme comunicar oficialmente la nota de la disolución antes de que el RD que la contiene la publicase en la Gaceta.

Debe así mismo, en nombre de los miembros que componían la Junta Delegada manifestar a S.M. el Rey, por medio de VE, nuestra gratitud por las bondadosas palabras de elogio que ha tenido para la Junta en el mismo decreto de su disolución.

Mas, también en cumplimiento de mi deber, he de significar con lealtad a VE que lamento sinceramente se

\footnotetext{
${ }^{23}$ ACVAG. Cuenca, 27.08.1928. El cardenal de Toledo al arzobispo

24 ACVAG. Cuenca, 31.07.1929. Ídem.

${ }_{25}$ Gaceta n. 168, 17 de junio de 1930. También en BOAV n, 8, 14.08.1930: 68 .
} de Valladolid. haya adoptado esta resolución. La Junta Delegada del Real Patronato, lejos de mermar en lo más mínimo los derechos de la Corona ni del Gobierno, facilitaba de un modo extraordinario la recta provisión de los cargos eclesiásticos. Estimo que dicha medida cederá en desprestigio del buen crédito que debe tener un Gobierno que aspira a procurar el bienestar de la Patria y desde luego puedo asegurarle que será recibida con desagrado por los buenos católicos españoles que han de ver en ella una desconsideración para la Iglesia.

He querido manifestar a VE estos mis personales sentimientos dentro del mismo terreno confidencial y oficioso de su carta, juzgando que, dadas las circunstancias por las que atraviesa la Patria, no procedía otra cosa". ${ }^{26}$

Una vez proclamada la República, el nuevo régimen instauraba otro sistema de relaciones entre la Iglesia y el Estado, para sustituirlo en breve por el modus operandi del franquismo establecido en el Concordato de 1953.

\section{LA CONFERENCIA DE METROPOLITANOS ESPAÑOLES (1921-1937)}

Desde que en 1920 Gandásegui presidió la archidiócesis castellana, estaba habilitado para participar en este organismo de la iglesia española nacido un año después. Ello significaba unir a las tareas pastorales otras preocupaciones que demandaban la voz unánime de la jerarquía eclesiástica mediante criterios y documentos gestados en la asamblea de metropolitanos. Esta finalidad se cumplió según las Actas de la Conferencia durante casi medio siglo, antes de nacer en 1966 la actual Conferencia Episcopal Española. ${ }^{27}$ Conforme indicó Elías Yanes, expresidente de la CEE, la creación de la Junta de Metropolitanos supuso un hito en el proceso organizativo de la jerarquía, a cuyo través todos los obispos quedaron, en cierta manera, implicados en responsabilidades colectivas. A lo largo de tres etapas, muy diferentes para la sociedad y la iglesia española contemporánea, las Actas son un escaparate singular de acuerdos, discusiones $y$, en su caso, silencios con que los arzobispos analizaron ciertos acontecimientos nacionales. Ahora, nuestro intento estriba en percibir la presencia y aportaciones del arzobispo Gandásegui dentro de este organismo que agrupa a todos los metropolitanos de España.

Junto con asuntos concretos, como fue la Democracia Cristiana, primó la necesidad de contar con una estructura sólida y reuniones periódicas. Aunque en sus primeros pasos las cuestiones debatidas fueron pocas, enseguida los prelados quedaron convencidos de su necesidad para aportar orientación concreta, tanto en asuntos eclesiales como sobre problemas y situaciones concernientes a la sociedad en general. Mucho más cuando la crisis social subió de tono. Ante ella, los obispos y la Santa Sede impulsaron este organismo que, en principio, se denominó "Junta de Reverendos Metropolitanos", y cauce representativo de todos los obispos españoles.

\footnotetext{
26 ACVAG, Documentos del doctor Gandásegui.

27 Cárcel Ortí, Vicente.1994. Madrid. En adelante: Acta y número de la sesión. Para el estudio histórico-jurídico: Actas y página.
} 
Aunque el compromiso inicial de reunir a los metropolitanos partió del cardenal primado Guisasola, su fallecimiento el 2 de septiembre de 1920 demoró la iniciativa. Será un año después cuando Tedeschini, nuevo nuncio en España, aporte su colaboración en esta tarea de impulsar la unidad de acción del episcopado español. También era deseo del secretario de Estado, cardenal Gasparri, quien consciente de la situación heredada en muchas diócesis exigía un organismo común regulador de todas ellas, así como fomentar una línea homogénea, y suficientemente respaldado desde Roma.

Sobre estos pilares, corresponderá al nuevo primado, recién trasladado desde la archidiócesis sevillana, el cardenal Enrique Almaraz Santos. Durante su breve gestión de la diócesis primada puso en pie este nuevo organismo. El pretexto era dirimir la diatriba entre integristas y demócratas, -"congregados a fin de deliberar sobre algunos problemas sociales que interesan sobremanera a esta porción escogida de la Iglesia católica"- asunto suficiente para presidir la primera conferencia de metropolitanos, reunida en Madrid el 10 de marzo de 1921. Interesa destacar que las conclusiones de aquella incipiente asamblea fueron redactadas por el arzobispo de Valladolid, monseñor Gandásegui y según costumbre remitidas a la Santa Sede para su aprobación. ${ }^{28}$

En principio, el nuevo organismo adoptó la forma de comité ejecutivo del episcopado, reunido por primera vez el 10 de marzo de $1921 .{ }^{29}$ Meses después pasó a discernir sobre aquellos temas aportados desde las provincias eclesiásticas. En años sucesivos, la nueva corporación irá cobrando fuerza como portavoz de todo el episcopado, que ofrecía a la opinión pública un conjunto de documentos colectivos aprobados por la Junta. Como fue en su arranque con los problemas suscitados por la Democracia Cristiana.

\section{El arzobispo Gandásegui en la Conferencia de Metropolitanos}

Otro sesgo tuvieron las relaciones de Gandásegui desde que se convierte en miembro del reducido grupo de metropolitanos en la iglesia española. En su historial este tramo ocupa tres lustros largos de su pontificado vallisoletano. Casi los mismos que, dentro de la $\mathrm{CME}$, compartirá tareas y preocupaciones con cinco cardenales presidentes de la conferencia y con los demás responsables de las archidiócesis españolas. $^{30}$

Respecto de los primeros, con el cardenal Almaraz, iniciador de las conferencias, apenas tuvo tiempo de confraternizar. No obstante, recibió la misión de redactar las conclusiones de la primera reunión presidida por el cardenal primado sobre la ortodoxia del grupo Democracia Cristiana se pronuncian los metropolitanos españoles con una postura menos tolerante que Roma, según el biógrafo ${ }_{28}$ Acta I, nn. 1-8.
29 Actas: 32 .
30 Con el arzobispo de Valencia se intercambia notas acerca del
periódico El Debate y escritos recibidos de El Siglo Futuro. Valencia 18.08.1922. de José Gafo. ${ }^{31}$ Mayor empatía se percibe con su sucesor, el cardenal Reig Casanova, que acrecentará como vocal en la Junta delegada del Patronato Regio. A este período corresponde un ir y venir de consultas previas cuyo fin era captar las preocupaciones de la provincia eclesiástica y ser su portavoz en la asamblea metropolitana. Con quien años atrás fuera obispo auxiliar en Valladolid y ahora cardenal primado Pedro Segura y presidente de la CME, compartió sucesivamente los problemas surgidos mientras los años postreros de la dictadura primorriverista -homenaje de adhesión a Su Majestad la Reina Madre- y en los albores de la Segunda República. Cualquier consejo era útil. Por ejemplo, dudoso de presidir un mitin de la Asociación diocesana de Padres de Familia, en el vallisoletano Teatro Calderón, el cardenal le responde: "No solo no veo dificultad sino que da autoridad al acto con su presencia e intervención. Vamos perdiendo oportunidad por cuantos medios en esta materia y es mi humilde parecer que debemos oponernos por cuantos medios están a nuestra mano al acaparamiento de la enseñanza y educación por parte del Estado, que continúa preso de la Institución Libre de Enseñanza, la cual en la actual situación ha adquirido una prepotencia incoercible. Es m criterio, pero VE podrá apreciar si las circunstancias....". ${ }^{32}$

Mayor afecto y constancia percibimos en el trato mantenido con el arzobispo de Tarragona y cardenal Vidal Barraquer, cuya relación epistolar fue más frecuente. ${ }^{33}$ Sobre todo, mientras éste presidió los dos organismos eclesiásticos nacionales, por enfermedad o ausencia de sus titulares. Así el cardenal de Tarragona pedirá a Gandásegui su opinión sobre la Asamblea Consultiva recién creada por Primo de Rivera y que convertía a los nueve arzobispos españoles en asambleístas por derecho propio (como habían sido en el Senado por el artículo 21 de la Constitución de 1876 hasta la República). La confianza entre ambos prelados hizo que le agradeciera su opinión acerca de un libro concreto, que el purpurado definía de antemano como "atrevido, inoportuno y contrario en absoluto a las normas y orientaciones pontificias y del Episcopado". La respuesta del prelado vallisoletano fue coincidente y no tuvo dificultad en expresar su adhesión al criterio emitido por Vidal.

Mayor enjundia presenta otras cuestiones. Por ejemplo, cuando solicita conocer su postura personal y de los sufragáneos acerca del documento colectivo que publicará antes de finalizar el año $1931 .^{34}$ Con la misma data, Gandásegui recibe "copia de la carta que me escribe el padre Gafo. Dígame Usted su parecer. He creído conveniente conociera dicha casta el Hermano de Madrid, además de los que

31 González, Etelvino. 2009. José D. Gafo Muñiz (1881-1936):206. Salamanca, Editorial Sanesteban.

32 ACVAG, Toledo 17.04.1930. Cardenal de Toledo al arzobispo de Valladolid.

33 Lo mismo en el tratamiento que siempre le dispensó que en la preocupación mutua, por la salud y la enfermedad de ambos durante este periodo.

${ }^{34}$ ACVAG, Tarragona 13.12.1931. Vidal Barraquer a Gandásegui. El cardenal solicita que haga todas las observaciones que estime oportunas, pues "ha procurado atender y harmonizar (sic) con el asentimiento de todos". 
forman la Comisión, por si debe entrevistarse con el dicho Padre". ${ }^{35}$ El asunto, que no era otro sino la postura de los sindicatos libres respecto de los comillistas (Gandásegui apostó por mantener la confesionalidad y el carácter mixto de los sindicatos), fue contestada desde Valladolid a los pocos días, según confirma el cardenal Vidal: ${ }^{36}$

"Recibí oportunamente su respuesta a la carta del Padre Gafo que me pareció conveniente remitirle días atrás. Hoy incluyo, para que conozca y al mismo tiempo dé su opinión, de lo que me dice el Obispo de Madrid, después de haberse entrevistado con él. Por ser asunto cosa delicada he remitido también al Señor Nuncio un ejemplar de esta copia para que se sirva consultar con la Santa Sede". ${ }^{37}$

Todo ello sin olvidar su preocupación por la salud del arzobispo vallisoletano, según escribe al canónigo Valero Caudevilla: "Sigo interesándome por la salud del queridísimo señor arzobispo, que por carecer de noticias, supongo mejorada con los días que van ya desde el ataque gripal. No dejo de encomendarle mucho al Señor". ${ }^{38}$ Cuando lo hace, el BOAV pareció llamar a rebato a toda la archidiócesis. Efectivamente, 1932 fue un año negro para la salud del arzobispo. Una enfermedad con altibajos que aparece en la mayoría de los boletines diocesanos del año. Bajo el epígrafe "Gratitud del prelado", reconocía los innumerables testimonios recibidos de la ciudad, archidiócesis y de todos los ámbitos de España: "durante el período agudo de su enfermedad aún siguen haciéndolos en estos días de franca mejoría". ${ }^{39}$ Idéntico sentimiento se hará constar un mes después, aunque el Boletín advierta deberse a los recibidos "con motivo de la operación quirúrgica a que ha sido sometido". ${ }^{40}$ Para volver dos meses más tarde a informar en la "Crónica diocesana" que:"habiendo sufrido un momentáneo proceso agudo la enfermedad de Su Excelencia reverendísima en las últimas horas del día 26 del pasado, y requeridos por él los facultativos sobre lo que era verdad del caso, el mismo prelado dispuso recibir el Santo Viático con toda solemnidad litúrgica". ${ }^{41}$ Sin embargo, era una mejoría incompleta, porque el 22 de julio "salió para San Sebastián, donde se halla en la clínica de San Ignacio atendiendo a su restablecimiento y a ser puesto en condiciones de sufrir una definitiva operación quirúrgica". ${ }^{42}$

35 El obispo Eijo Garay se entrevistará, como años antes lo hiciera el cardenal Reig, con el dominico Gafo, y reconoce la doble realidad (profesional y católica-comillista) y la dificultad de unirse ambos grupos, aunque simpatizaba con Gafo. Mientras que Gandásegui seguía al jesuita Nevares y los católicos sindicalistas de Valladolid, sostenía una prevención respecto de las tesis de Gafo que pudo mostrar al cardenal Vidal. González, Etelvino. 2009: 443.

36 Berzal, Enrique. 1999: 46.

37 ACVAG, Tarragona 02.01.1932. Cardenal Vidal al arzobispo Gandásegui.

38 ACVAG, Tarragona 05.06.1932. Cardenal Vidal a Valero Caudevilla.

39 BOAV no 2, 15.03.1932: 29.

40 BOAV no 3, 15.04.1932: 37

41 BOAV no 5, 22.06,1932: 59.

42 BOAV no 6,10.08.1932: 68. También n. 7, 27.09.1932.
Y es que Gandásegui fue un prelado que tomó muy en serio la responsabilidad dentro de la Conferencia, lamentando que la enfermedad merrmase su actividad. Así dejó escrito: "me contraría grandemente no haber podido asistir y lamento no poder intervenir en los trabajos, sobre todo en estas circunstancias". Una vez repuesto, pero sin incorporarse a las sesiones de la $\mathrm{CME}$, Vidal le seguirá teniéndole al día sobre los asuntos concernientes a este organismo, al tiempo que lamentará la ausencia de Gandásegui:" para aportar a la CME sus valiosos criterios y orientación en puntos tan delicados como debían tratar". ${ }^{43}$

Cierra este circuito el tiempo correspondiente al cardenal Gomá, cuya presidencia coincide con los años en que la salud cada vez más quebrantada del arzobispo vallisoletano y su fallecimiento. ${ }^{44}$ El trato comienza desde que asume la responsabilidad de la sede primada, y con ella la condición de vocal de la Conferencia de Metropolitanos, todavía sin ser cardenal (lo sería en el Consistorio del 19 de diciembre de 1935)..$^{45}$ La política republicana -singularmente en la fase frentepopulista- y los tres primeros trimestres de la Guerra Civil centran las comunicaciones entre ambos prelados. $^{46}$

43 ACVAG, Tarragona 20.12.1933.

44 Debido a la Guerra Civil se demoró la convocatoria. Reunida en noviembre de 1937, y presidida por primera vez por el cardenal Isidro Gomá, quien expuso:"los motivos que le habían inducido a convocar la Conferencia de Metropolitanos, después de dos años de no haberse celebrado ninguna por lo anormal de las circunstancias, a saber: la extrema gravedad de los hechos que en el orden religioso, político y social han ocurrido desde julio de 1936; la conveniencia de que los reverendísimos metropolitanos estén al corriente de los sucesos culminantes que se han desarrollado en la vida religiosa del país y en los que especialmente ha debido intervenir el señor Presidente por su carácter de Primado". Acta XXII (1937), pgs. 387-388.

45 ACVAG, Toledo 03.07.1933. Isidro, arzobispo de Toledo a Remigio Gandásegui, arzobispo de Valladolid. "Hecha en el día de ayer mi entrada en esta Archidiócesis de Toledo, me apresuro a ofrecerme a VE para cuanto quiera mandarme en este cargo que la benevolencia de la Santa Sede ha tenido a bien otorgarme". La respuesta en la vuelta de la hoja; Gandásegui le felicita y agradece el ofrecimiento y le expresa su colaboración.

46 ACVAG, Guadalajara 18.05.1936. Gomá responde a la carta de Gandásegui del día 9 y lo hace desde esta ciudad en donde está haciendo la visita pastoral. "Pienso como Usted sobre la gravedad de la situación que nos han creado las ocurrencias políticas y es conveniencia de que, para que no se agraven más, siga siendo el actual señor Nuncio quien trate las cosas de la Iglesia en su relación con el Estado o sus autoridades, dadas sus reconocidas dotes de talento, experiencia y exquisito trato que todos le reconocemos (...) Espero la remesa de los temas de esa Provincia y que podamos departir sobre nuestras cosas, tanto y tan graves". 
CONFERENCIA DE METROPOLITANOS ESPAÑOLES ASISTENCIA A LAS SESIONES

\begin{tabular}{|c|c|c|c|c|c|c|c|c|c|c|c|}
\hline Presidente $^{47}$ & 1 & 2 & 3 & 4 & 5 & 6 & 7 & 8 & 9 & 10 & 11 \\
\hline Cardenal Almaraz, arzo preconizado de Toledo & + & & & & & & & & & & \\
\hline Cardenal Reig,, arzobispo de Toledo & & + & + & + & + & + & + & + & + & & \\
\hline Cardenal Vidal, arzobispo de Tarragona & & & & & & & & & & +48 & + \\
\hline \multicolumn{12}{|l|}{ Cardenal Segura, arzobispo de Toledo } \\
\hline \multicolumn{12}{|l|}{ Vocales } \\
\hline Cardenal Vidal, arzobispo de Tarragona & + & + & + & + & + & + & + & + & + & & \\
\hline Cardenal Soldevilla, arzobispo de Zaragoza & + & + & & & & & & & & & \\
\hline Cardenal Benlloch, arzobispo de Burgos & & & & + & & + & & & & & \\
\hline E. Ilundain, arzobispo de Sevilla ${ }^{49}$ & & & + & + & + & + & + & + & + & + & \\
\hline V. Casanova, arzobispo de Granada ${ }^{50}$ & & & + & + & & + & + & + & + & + & + \\
\hline R. Gandásegui, arzobispo de Valladolid ${ }^{51}$ & + & + & + & + & + & + & + & + & + & + & $\mathrm{NO}$ \\
\hline P. Melo, arzobispo de Valencia & & & + & + & + & + & + & + & + & + & + \\
\hline M. Lago, arzobispo de Santiago & & & & + & + & & & & & & \\
\hline J. de Diego, arzobispo de Santiago & & & & & & & + & + & + & & \\
\hline R. Doménech, arzobispo de Zaragoza & & & & & & & & + & & & \\
\hline P. Segura, arzobispo de Burgos & & & & & & & & & & + & + \\
\hline
\end{tabular}

\begin{tabular}{|c|c|c|c|c|c|c|c|c|c|c|}
\hline Presidente & $12^{52}$ & 13 & 14 & 15 & 16 & 17 & 18 & 19 & 20 & 21 \\
\hline Cardenal Vidal, arzobispo de Tarragona & & & & & + & + & + & + & + & + \\
\hline Cardenal Segura, arzobispo de Toledo & $++^{53}$ & + & & + & & & & & & \\
\hline \multicolumn{11}{|l|}{ Cardenal Gomá, arzobispo de Toledo ${ }^{54}$} \\
\hline \multicolumn{11}{|l|}{ Vocales } \\
\hline Cardenal Vidal, arz음 de Tarragona & + & + & + & + & & & & & & \\
\hline Cardenal Casanova, arz으 de Granada & + & & & & & & & & & \\
\hline Cardenal Ilundain, arzobispo de Sevilla & & & & & & & & & & ++ \\
\hline I. Gomá, arzobispo de Toledo & & & & & & & ++ & ++ & ++ & ++ \\
\hline R. Pérez, Patriarca de Indias ${ }^{55}$ & & & ++ & + & ++ & ++ & & & & \\
\hline R. Gandásegui, arzobispo de Valladolid & ++ & ++ & ++ & ++ & ++ & no & no & no & no & ++ \\
\hline P. Melo, arzobispo de Valencia & ++ & & ++ & ++ & ++ & ++ & ++ & ++ & ++ & ++ \\
\hline R. Doménech, arzobispo de Zaragoza & ++ & & ++ & ++ & ++ & ++ & ++ & ++ & ++ & ++ \\
\hline J. de Diego arzobispo de Santiago & & & ++ & & & & & & & \\
\hline Z. Martínez, arzobispo de Santiago & ++ & & & & ++ & & & & & \\
\hline M. Castro, arzobispo de Burgos & ++ & & ++ & ++ & ++ & ++ & ++ & ++ & ++ & ++ \\
\hline T. Muñiz, arzobispo de Santiago & & & & & & & & & & ++ \\
\hline A. Parrado, arzobispo de Granada & & & & & & & & & ++ & ++ \\
\hline \multicolumn{11}{|l|}{ Representantes de provincias eclesiásticas } \\
\hline Granada: Obispo de Jaén & & & + & + & + & + & + & + & + & \\
\hline Toledo: Obispo de Sigüenza & & & & & + & + & & & & \\
\hline Santiago: Obispo de Oviedo & & & & & & ++ & ++ & ++ & ++ & \\
\hline Valladolid: Obispo de Ávila & + & & & & & ++ & & & ++ & \\
\hline Valladolid: Obispo de Astorga & & & & & & & ++ & ++ & & \\
\hline \multicolumn{11}{|l|}{ Tarragona: Obispo de Solsona } \\
\hline Zaragoza: Obispo de Jaca & & & & & & & & & & \\
\hline
\end{tabular}

47 La Presidencia estuvo en estos años ocupada fundamentalmente por los cardenales Reig Casanova, Vidal Barraquer. El cardenal Segura sólo la ocupó tres veces. En la última (ya en tiempo de la Guerra Civil), la presidencia pasa a Isidro Gomá.

48 Comienza a presidirla por enfermedad del cardenal Reig, que fallecerá el 25 de agosto de 1927.

49 A partir de la conferencia VII, nombrado cardenal por Pío XI el 30.03.1925.

50 Cardenal a partir de la conferencia VII, nombrado cardenal por Pío XI el 30.03.1925.

51 La ausencia del arzobispo Gandásegui en las cuatro sesiones de 1932, 1933 (1a), 1933 (2a), 1934. Estará presente, por última vez, en la reunión celebrada en 1935. Enrique Plá y Deniel (como obispo de Salamanca) sigue representando a la provincia eclesiástica, después de la muerte de Gandásegui, en 1937.

52 Concurren los nueve metropolitanos de las provincias eclesiásticas y preside el Primado.

53 Presidente por primera vez.

54 Como arzobispo entra en la diócesis primada el 2 de junio de 1933 (carta de ofrecimiento al arzobispo Gandásegui el 03.07. 1933). Cardenal por el papa Pío XI el 16.12.1935.

55 Por primera vez acodado por la Santa Sede "en atención a su especial jurisdicción palatina y castrense"; jurisdicción suprimida durante la República. 


\begin{tabular}{|c|c|c|}
\hline CONFERENCIA & LUGAR & FECHAS \\
\hline 1 & Madrid $^{13}$ & 10.03 .1921 \\
\hline 2 & Madrid & $04 / 07.02 .1923$ \\
\hline 3 & Madrid & $12 / 15.12 .1923$ \\
\hline 4 & Madrid & 23/26.04.1924 \\
\hline 5 & Madrid & 25/27.11.1924 \\
\hline 6 & Madrid & $31 / 01.04 .1925$ \\
\hline 7 & Madrid & $15 / 17.10 .19255$ \\
\hline 8 & Madrid & 28/30.04.1926 \\
\hline 9 & Toledo & 21/23.10.1926 \\
\hline 10 & Madrid & $18 / 20.05 .1927$ \\
\hline 11 & Madrid & 09.10 .1927 \\
\hline 12 & Madrid & $16 / 18.10 .1928^{14}$ \\
\hline 13 & Madrid & 17/19.11.1929 \\
\hline 14 & Madrid & 29/31.10.1930 \\
\hline 15 & Toledo & 09.05 .1931 \\
\hline 16 & Madrid & 18/20.11.1931 \\
\hline 17 & Madrid & 03/06.11.1932 \\
\hline 18 & Madrid extraordinaria ${ }^{15}$ & $27 / 30.06 .1933$ \\
\hline 19 & Madrid & 21/26.10.1933 \\
\hline 20 & Madrid & 15/18.11.1934 \\
\hline 21 & Madrid & 12/16.11.1935 \\
\hline 22 & Abadía de Dueñas (Palencia) & 10/13.11.1937 \\
\hline
\end{tabular}

renovada periódicamente entre los arzobispos. A pesar de estar comprometido con las tareas de la Conferencia, Gandásegui únicamente quiebra la asistencia por enfermedad, según sucedió en las reuniones XVII-XX.

Aunque, cuando hablamos de una tarea coral o mancomún como sucede con la $\mathrm{CME}$, es difícil distribuir ni aproximadamente distribuir los méritos correspondientes a cada persona, respecto de Gandásegui hay pistas suficientes para apreciar su aportación más directa, sin excluir el quehacer "coral" en acuerdos unánimes de la Conferencia. ${ }^{59}$ Otros prelados parecen confirmarla cuando se muestran pendientes de la salud del arzobispo y, en su caso, lamentan no disponer de su atinado consejo, que todos apreciaban. Veamos algunos ejemplos con respaldo documental que desvelan el papel directo del arzobispo vallisoletano. Siempre sin olvidar aquellos otros oficiales colectivos y unánimes, que publican los boletines de las diócesis.

Entre los primeros hallamos la redacción de las conclusiones que constan en las actas de la primera Conferencia. Por su relieve merece la pena exhumar la correspondencia cruzada con el cardenal Vidal Barraquer ante la novedad que suponía la Asamblea Nacional instituida por el General Primo de Rivera. ${ }^{60}$ En concreto, cuando el cardenal le pide conteste a estas preguntas, que suponen una cierta sospecha ante las medidas adoptadas por la dictadura. Gandásegui debía contestar a las siguientes preguntas: "1a. ¿Cree debemos aceptar el cargo de asambleísta? 2a. ¿Debemos asistir a la inauguración? 3a. Conviene cambiar impresiones de todos los metropolitanos convocando una conferencia un día antes de la fecha de la inauguración".

Lo cierto fue que el cardenal Vidal presidirá en Madrid la XI Conferencia el 9 de octubre de 1927, víspera de inaugurarse la Asamblea Nacional. Junto con el presidente concurrieron el cardenal arzobispo de Granada y los arzobispos de Valencia y Burgos. "Por imposibilidad de asistir" no están los arzobispos de Valladolid y de Zaragoza, y por enfermedad el cardenal arzobispo de Sevilla. No obstante, los reunidos aprueban dos acuerdos sobre la participación en la Asamblea:

1‥ Reconoce la importancia de intervenir el Episcopado en la Asamblea, siempre que la Santa Sede lo estime oportuno, designa una comisión permanente: "que vigile, actúe e informe a los prelados asambleístas y a todos los prelados de España cuando las circunstancias lo reclamen". Estará formada por los arzobispos de Valladolid, Valencia, Burgos y el Obispo de Madrid-Alcalá, encargados de formular un anteproyecto de asuntos que deberán llevarse a la Asamblea y relacionados con los intereses de la Iglesia (moralidad, enseñanza, asignación del culto y clero,

56 En principio se reúne en el Palacio de la Comisaría general de la Cruzada Después en la Residencia del Corazón de María (Buen Suceso).

57 Es la primera vez en que la Conferencia tiene única convocatoria anual: "según las indicaciones hechas oralmente al eminentísimo señor cardenal de Tarragona de que se celebre una conferencia única al año. He pensado que sería el tiempo más oportuno el de los últimos días de septiembre". ACVAG, Cuenca 27.08.1928. Cardenal Segura a arzobispo Gandásegui. Aunque ese era el proyecto, la Conferencia se retrasó hasta mediados del mes siguiente.

58 Asiste Gomá como arzobispo preconizado de Toledo. Convocatoria extraordinaria debido a la nueva Ley de Confesiones y por los graves problemas que plantea.

59 Antes de proclamarse la República, pueden catalogarse así: las protestas ante la inmoralidad de la vestimenta femenina, la preocupación por la Buena Prensa, la Enseñanza y Catequesis, reorganización de la Acción Católica, litigios entre comunidades religiosas y obispados, protesta por la situación creada a la Iglesia en México, los temores ante los Clubes Rotarios... Mayor entidad debe atribuirse a las decisiones y documentos colectivos emitidos durante la etapa republicana anteriores al fallecimiento de Gandásegui.

60 ACVAG, Tarragona 26.09.1927. Cardenal Vidal a arzobispo Gandásegui. 
impuestos, etc.). ${ }^{61}$ Estas orientaciones encajan la actividad del prelado vallisoletano. Efectivamente, en varias ocasiones, los metropolitanos encomendarán a Gandásegui la ponencia referente a ciertos asuntos económicos, y sobre ellos lucirá sus cualidades oratorias en la Asamblea plenaria reunida en diciembre de 1928.

La cuestión de los sacerdotes asambleístas provoca el siguiente acuerdo:

20. "Dados los perjuicios que pudieran seguirse de la designación de sacerdotes para intervenir en la Asamblea Nacional, si estos no son en absoluto recomendables por su espíritu sacerdotal y cualidades de virtud, ciencia y prudencia, aparte del cumplimiento de las disposiciones canónicas vigentes, se acordó interesar del Gobierno de Su Majestad la medida general de que se requiera el plácet del Ordinario para la designación de los sacerdotes, bien sea para este cargo de asambleísta, bien para cualquier otro cargo público que no sea de carácter estrictamente sacerdotal". ${ }^{62}$ En el seno de la Asamblea, Gandásegui pronunciará un memorable discurso, en la sesión plenaria celebrada el 12 de diciembre de 1928, en defensa del aumento de los haberes del Clero -cuyo texto íntegro publica el BOAV-. ${ }^{63}$ Cuanto expuso a los asambleístas tenia por precedente las gestiones que le asignó la Conferencia de Metropolitanos y Gandásegui ejecuto eficazmente. Nos referimos a cuanto sigue:

Bajo la presidencia del cardenal Reig, la CME decidió presentar al Presidente del Directorio un escrito:"(para) que mejore la aflictiva situación económica por que atraviesa el clero, elevando al efecto sus asignaciones en el Presupuesto del Estado; petición que, convencidos de la plena justicia en que se fundamenta hacen suya los metropolitanos". De la gestión se encargará una Comisión formada por el arzobispo de Valladolid y los obispos de Segovia y Madrid-Alcalá. ${ }^{64}$ En la reunión de noviembre del año siguiente el arzobispo de Valladolid, como presidente de la "Comisión mixta para recabar la indemnización a las comunidades religiosas por los bienes indebidamente desamortizados". ${ }^{65}$ Allí dará cuenta de los trabajos realizados (escritos al ministro Calvo Sotelo, revisión de expedientes en el Ministerio de Hacienda) desde $1921 .^{66}$ A ello añadimos otra encomienda de la CME consistente en gestionar ante la dirección general de Registros un decreto para que no se precise acreditar la excepción de la desamortización para inscribir en el Registro la mera posesión de dichos bienes. ${ }^{67}$ Suficientes acciones, a mi entender, para que la CME reconociese la eficacia con que

61 Acta XI no. 302. Esta misma comisión será la encargada de estudiar las modificaciones oportunas en la Junta Delegada del Real Patronato, en donde también ejerce sus funciones el arzobispo Gandásegui.

62 Acta XI, №. 307.

63 BOAV no. 12, 30.12.1928: 165-179. Según apostilla el redactor del Boletín: "El éxito de este magnífico y notable discurso se ha extendido y traspasado las fronteras de nuestra Patria. Sus resultados legales inmediatos han sido el aumento de la asignación del Clero Parroquial, elevando a más de tres millones de pesetas la suma de millón y medio que para estos tenía el Gobierno. Como sincero homenaje de admiración y adhesión al excmo. señor Arzobispo por esta brillantísima gestión, el Clero de la ciudad acudió en unánime y espontánea manifestación a esperar la llegada de S.E. el día 15, tributándole a su bajada del tren un cordialísimo recibimiento, que el Prelado agradeció en breves y emocionadas frases, significando que su gestión la consideraba cono parte de su ministerio pastoral".

64 Acta VI (abril 1925), №. 168.

65 Acta IX, n‥ 248.

${ }_{66}$ Acta II (febrero 1923), no. 30

67 Acta XI (octubre 1927), №. 307.
Gandásegui rubricó cuantas tareas le encomendaron los metropolitanos.

Durante la República crecen los documentos y acuerdos gestados por el consorcio de los metropolitanos, que el prelado hace públicos en el boletín diocesano. Desde primera hora destacan algunos: Circular sobre el respeto y obediencia a los poderes constituidos. ${ }^{68}$ Casi sin interrupción aparecieron otros. ${ }^{69}$ Todos ellos salen con premura de la conferencia celebrada el 9 de mayo de 1931 y presidida por el cardenal Segura, sustituido en las siguientes por el cardenal Vidal. ${ }^{70}$ Será en la Conferencia de noviembre de 1931 cuando como presidente aprovechará la reunión para decir:

\begin{abstract}
"Una vez consignadas las anteriores deliberaciones y acuerdos recaídos, la conferencia consideró propio y oportuno finalizar el acto oficial de la misma con la expresión de su pesar y condolencia por haberse dejado de contar en su seno al excelentísimo señor cardenal Segura, que tantas veces la había dignamente presidido, y hacer propios los elogios y sentimientos del Papa en la carta de aceptación de su renuncia al Arzobispado de Toledo, la cual, una vez publicada en Acta Apostólica Sedis, será insertada en los Boletines Oficiales Diocesanos". ${ }^{71}$
\end{abstract}

Cuando asiste nuevamente a la Conferencia (12-16 noviembre 1935), Gandásegui actuará como ponente, junto con el arzobispo de Santiago, del tema IV titulado "Disciplina eclesiástica" que comprende una amplia panoplia de asuntos. ${ }^{72}$ La mayoría de ellos incomprensibles para la mentalidad actual.

\section{BiBLIOGRAFÍA}

Andrés-Gallego, José. 1999. La Iglesia en la edad contemporánea. 1. 1800-1973. Madrid: Ediciones Encuentro.

Berzal de la Rosa, Enrique. 1999. Remigio Gandásegui (1905-1937). Un obispo para una España en crisis, Madrid: BAC.

Cárcel Ortí, Vicente. 1988. "Iglesia y Estado durante la Dictadura de Primo de Rivera". Revista de Derecho Canónico vol. 45:215.

Cárcel Ortí, Vicente. 1995. "Ejercicio del privilegio de presentación de obispos por el general Franco". Il Atti del X syumposium canonistico-romano: 24-128.

Cárcel Ortí, Vicente (editor). 1994. Actas de la conferencia de metropolitanos españoles (1921-1965). Madrid: BAC.

68 BOAV no extra 27.04.1931. Nota de la Nunciatura que el arzobispo hace suya en todos los puntos.

69 BOAV no. 6, 20.06.1931:63-65. Declaración colectiva pastoral de los metropolitanos en nombre propio y conforme al sentir del Episcopado. BOAV n. 8,16.08.1931:79. Sobre la situación religiosa presente y deberes de los católicos. BOAV n. 11, 28.11.1931:115ss. Carta pastoral colectiva del Episcopado a los fieles ante la situación creada por la Constitución. BOAV n. 5, 22.06.1932: 56-57. Mensaje de los prelados portugueses a los españoles.

70 Acta XV, nn. 423-431.

71 Acta XVI, n‥ 451.

72 Acta XXI (1935) nn. 588-600. 
González, Etelvino. 2009. José D. Gafo Muñiz (18881936). Salamanca: editorial Sanesteban.

Palomares Ibáñez, Jesús María. 1993. La dictadura de Primo de Rivera en Valladolid. Valladolid: Universidad.

Palomares Ibáñez, Jesús María. 1996. “De la tranquilidad a los años difíciles: el arzobispo Gandásegui (1920-1937)". Historia de la diócesis de Valladolid, Valladolid: Arzobispado.

Zamora García, Francisco José. 2011. “Los nombramientos episcopales durante la Dictadura del general Primo de
Rivera, Anuario Jurídico y Económico Escurialente XLIV: 551-566.

Otras fuentes

Archivo de Curia del arzobispado de Valladolid. Documentos del arzobispo Gandásegui.

Boletín Oficial del Arzobispado de Valladolid (1920-1937). 